\title{
Dermatomicose e ceratite micótica causada por Exophiala sp em um cão
}

\author{
Dermatomycosis and mycotic keratitis caused by Exophiala sp in a dog
}

\author{
Paula Cristina Basso ${ }^{\text {I* }}$ Alceu Gaspar Raiser ${ }^{\text {II }}$ Claudete Schmidt ${ }^{\text {II }}$ Maurício Veloso Brun ${ }^{\text {III }}$ \\ Tatiana Mello de Souza' Anelise Bonilla Trindade ${ }^{\mathrm{IV}}$ Daniel Curvello de Mendonça Müller $^{\mathrm{I}}$
}

\begin{abstract}
Neste trabalho, descreve-se o diagnóstico e a conduta terapêutica aplicada em caso de dermatomicose e ceratite micótica causada por Exophiala sp em um cão com um ano e seis meses de idade. Os sinais clínicos incluíam alopecia, crostas, despigmentação e ulceração do plano nasal e focinho, e ceratite superficial bilateral no canto lateral dos olhos. $\mathrm{Na}$ cultura fúngica foi isolado Exophiala sp e o exame histopatológico da biopsia cutânea revelou dermatite nodular superficial e profunda granulomatosa. O tratamento com itraconazol sistêmico promoveu remissão dos sinais clínicos. Conclui-se que a realização de cultura fúngica e biópsia de pele são exames complementares eficazes no diagnóstico de dermatomicoses e que o emprego de itraconazol sistêmico pode ser efetivo no tratamento de dermatite fúngica e ceratite micótica causado por Exophiala sp em cão.
\end{abstract}

Palavras-chave: doenças fúngicas de pele, infecção corneana micótica, fungos dematiáceos.

\section{ABSTRACT}

This report describes the diagnosis and the therapeutic conduct applied to the cases of subcutaneous dermatomycosis and mycotic keratitis caused by Exophiala sp in a one and a half year-old dog. The clinical signs included alopecia, crusts, dispigmentation, ulcerations in the nose and superficial bilateral keratitis in the corner of the eyes. In the fungal cultures, Exophiala sp was isolated and the microscopic analysis revealed characteristics of fungal dermatitis. Systemic therapy with itraconazole evidenced remission of clinical signs.
The realization of fungal cultures and cutaneous biopsy are efficient complementary procedures in the diagnosis of dermatomycosis and that the usage of oral itraconazole can be effective in the treatment of fungal dermatitis and mycotic keratitis caused by Exophiala sp in dogs.

Key words: skin mycotic disease, corneal infection mycotic, dermatiaceous fungal.

As micoses superficiais são, sem dúvida, as enfermidades mais comuns causadas por fungos em cães e gatos no mundo ocidental (ROCHETTE et al., 2003) e envolvem apenas as camadas superficiais da pele, os folículos pilosos e as unhas (SCOTT et al., 1996). As micoses subcutâneas são incomuns no atendimento clínico dermatológico (JAND \& GUPTA, 1989) e se caracterizam pela presença de granulomas ou piogranulomas na derme e no tecido subcutâneo (HERRÁEZ et al., 2001), ao passo que as micoses sistêmicas são infecções de órgão internos que podem disseminar-se secundariamente por via hematógena para a pele (SCOTT et al., 1996).

Exophiala é um gênero de fungos dematiáceos envolvido como agente etiológico de micoses subcutâneas (SILVA et al., 2005). Entre as espécies mais isoladas encontram-se $\boldsymbol{E}$. jeanselnei e $\boldsymbol{E}$. dermatitidis (FERREIRA et al., 2006). Esses fungos são

IPrograma de Pós-graduação em Medicina Veterinária (PPGMV), Centro de Ciências Rurais (CCR), Universidade Federal de Santa Maria (UFSM), Santa Maria, RS, Brasil. *Endereço para correspondência: Rua São Boaventura, 31, Bairro São Geraldo, 98700000, Ijuí, RS, Brasil. E-mail: paula.basso@bol.com.br.

"Departamento de Clínica de Pequenos Animais (DCPA), CCR, UFSM, Santa Maria, RS, Brasil.

IIIDCPA, Faculdade de Agronomia e Medicina Veterinária (FAMV), Universidade de Passo Fundo (UPF), Passo Fundo, RS, Brasil.

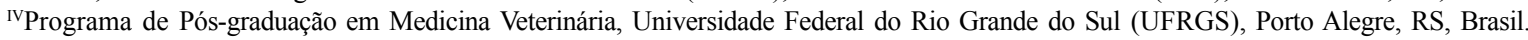


intensamente pigmentados (CORRADO et al., 1982) e podem produzir três diferentes tipos de infecção: feoifomicose, cromoblastomicose e micetoma, de acordo com suas características histopatológicas (GARCIA-MATOS et al., 2002).

As manifestações clínicas da infecção por esses microorganismos incluem alopecia, crostas e nódulos solitários subcutâneos, freqüentemente ulcerados, afetando especialmente as extremidades (SUH, 2005). A ceratite micótica é rara no cão e ela pode ser ulcerativa ou não-ulcerativa. Candida albicans, Aspergillus e Alternaria são os fungos mais comumente isolados (GELATT, 2003). Fungos dematiáceos foram identificados no tecido ocular de dois gatos e um cão, na forma clínica de uveíte, glaucoma e ceratite, respectivamente (BERNAYS \& PEIFFER, 1998).

Os achados histopatológicos se caracterizam por dermatite nodular a difusa, granulomatosa ou piogranulomatosa e paniculite, sendo que poderão estar presentes inúmeros elementos fúngicos (SCOTT et al., 1996). Os fungos do gênero Exophiala crescem em sabouraud dextrose agar a 25 a $35^{\circ} \mathrm{C}$ e as biópsias por saca-bocado são o material preferido para cultura (SUH, 2005).

A excisão cirúrgica de lesões solitárias pode ser curativa (SUH, 2005). O cetoconazol sistêmico foi usado sozinho ou em combinação com flucitosina, com respostas variadas (SCOTT et al., 1996). KETTLEWELL et al. (1989) relataram resistência ao cetoconazol em lesão cutânea causada por Exophiala spinifera em felino, demonstrando, no entanto, boa resposta com flucitosina. Em humanos, o itraconazol em altas doses tem mostrado melhores resultados (BONIFAZ et al., 2004). Terapia com posoconasole resultou em sucesso no tratamento de pacientes humanos com eumicetoma e cromoblastomicose refratárias às terapias padrões, sugerindo uma opção de tratamento importante nessas doenças (NEGRONI et al., 2005). Nos casos não responsáveis à quimioterapia com antifúngicos orais pode-se associar termoterapia e/ou criocirurgia (CASTRO et al., 2003).

Em virtude da baixa ocorrência, da diversidade clínica e acima de tudo das mais variadas respostas manifestadas por fungos do gênero Exophiala aos tratamentos antifúngicos empregados, o presente relato tem por objetivo descrever um caso de dermatomicose e ceratite micótica causada por Exophiala $\boldsymbol{s p}$ em cão, enfatizando principalmente a abordagem prática do diagnóstico e da terapia instituída.

Um cão, macho, de raça Collie, com um ano e seis meses de idade, foi apresentado com lesões dermatológicas associadas com alteração ocular há trinta dias. Ele havia sido tratado com cefalexina $30 \mathrm{mg}$ $\mathrm{kg}^{-1}$, BID, durante 15 dias e colírio de dexametasona, sulfato de neomicina e sulfato de polimixina $B$, a cada seis horas, no mesmo período de tempo, não demonstrando qualquer melhora no quadro clínico. Segundo relato do proprietário, as lesões cutâneas eram não-pruriginosas e iniciaram no plano nasal juntamente com as lesões oculares. Ao exame físico, o paciente apresentava-se alerta, em bom estado nutricional, clinicamente hidratado e os sinais vitais dentro de parâmetros normais. Verificou-se alopecia, crostas, despigmentação e ulceração cutânea no plano nasal, despigmentação e ulceração do focinho, e ceratite superficial bilateral e simétrica localizadas no canto lateral dos olhos (Figura 1).

O hemograma revelou contagem de células vermelhas e brancas dentro dos valores padrão de normalidade ( $45 \%$ de hematócrito; $6,2 \mathrm{~g} \mathrm{dl}^{-1}$ de proteína plasmática total; 11510 leucócitos totais $\mu^{-1} ; 600$ eosinófilo, $\mu \mathrm{l}^{-1}$; 1322 linfócitos $\mu \mathrm{l}^{-1} ; 106$ monócitos $\left.\mu \mathrm{l}^{-1}\right)$. Os parâmetros bioquímicos de avaliação hepática (alanina aminotransferase: $50 \mathrm{UI} \mathrm{L}^{-1}$; fosfatase alcalina: 110UI L ${ }^{-1}$; albumina: $3,2 \mathrm{~g} \mathrm{dl}^{-1}$ ) e renal (uréia: $30 \mathrm{mg} \mathrm{dl}^{-1}$; creatinina: $1,1 \mathrm{mg} \mathrm{dl}^{-1}$ ) também se encontravam dentro do limite normal.

Realizou-se exame parasitológico de raspado de pele profundo e cultura fúngica de pêlos e crostas. Para a cultura, o material foi plaqueado em agar dextrose Sabouroud a $25^{\circ} \mathrm{C}$, durante quatro semanas com posterior identificação por meio de testes morfológicos e bioquímicos. $\mathrm{O}$ exame parasitológico demonstrou resultado negativo, mas na cultura fúngica foi isolado Exophiala sp.

O tratamento com cetoconazol ${ }^{\mathrm{a}}$ oral $(10 \mathrm{mg}$ $\left.\mathrm{kg}^{-1}\right)$, BID, durante trinta dias foi ineficiente e o paciente retornou com vômito, possivelmente em conseqüência da administração do fármaco, ocasião em que foi feita biópsia cutânea e nova cultura fúngica.

Histologicamente, a lesão se caracterizava por proliferação acentuada de linfócitos, plasmócitos e macrófagos epitelióides organizados na forma de nódulos na derme superficial e profunda, obliterando os anexos cutâneos. Na cultura fúngica isolou-se Alternaria sp.

Foi então iniciada terapia com itraconazol ${ }^{\mathrm{b}}$ (10 $\left.\mathrm{mg} \mathrm{kg}^{-1}\right)$, por via oral, uma vez ao dia, durante noventa dias, e banhos semanais com xampu de cetoconazol $^{c}$. A ceratite regrediu após 30 dias de tratamento com itraconazol sistêmico, as lesões cutâneas no plano nasal regrediram completamente em 60 dias e aos 90 dias a ulceração nasal já se encontrava cicatrizada. Nesse período, realizou-se novamente

Ciência Rural, v.38, n.7, out, 2008. 


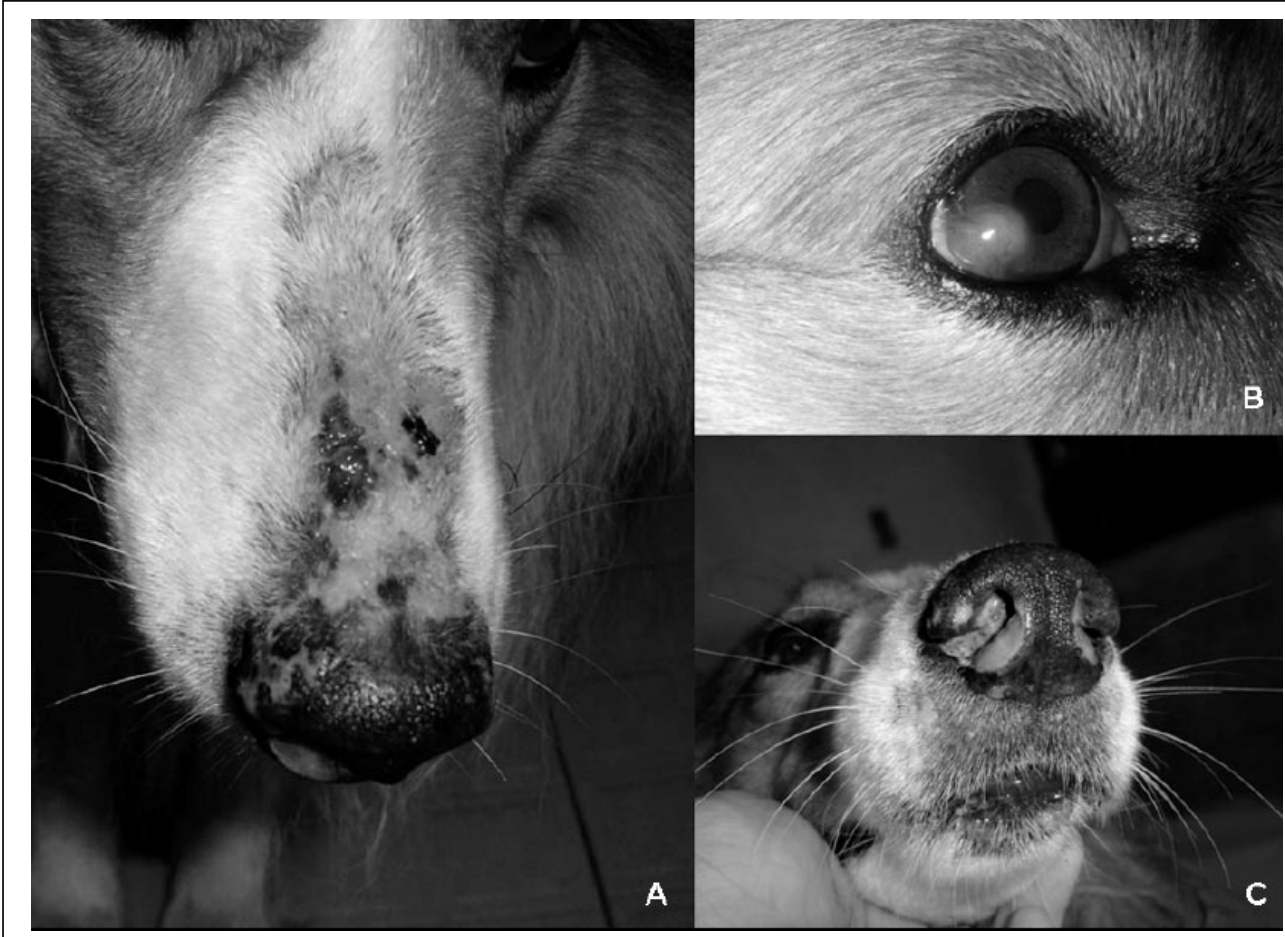

Figura 1 - (A) Canino macho da raça Collie apresentando ceratite superficial localizada no canto lateral do olho. (B) Evidencia-se alopecia, crostas, ulceração e despigmentação cutânea no plano nasal. (C) Lesões ulcerativas no focinho causadas por fungo do gênero Exophiala sp.

cultura fúngica, a qual demonstrou resultado negativo. A partir daí o tratamento foi suspenso pela remissão completa dos sinais clínicos dermatológicos, no entanto, mesmo com a regressão dos sinais oculares, permaneceu ainda delgado feixe vertical de cicatriz corneana bilateral.

Os fungos dermatiáceos compreendem um grupo de organismos profundamente pigmentados, que ganham acesso ao hospedeiro por meio da pele lesionada (BOULJIHAD et al., 2002). Para MARIN et al. (2006), a infecção por esses agentes é mais comum em pacientes com doenças concomitantes e imunossuprimidos, mas nenhum fator predisponente foi identificado neste caso, pois se tratava de um canino jovem, vacinado, sem histórico de ferida traumática, de terapia prolongada com corticosteróides e/ou antibióticos ou doenças debilitantes crônicas. Considera-se que a infecção tenha se instalado neste paciente possivelmente em virtude da demora no desenvolvimento de imunidade adequada pelos hospedeiros jovens, conforme citado por SCOTT et al. (1996).

KANO et al. (2000) descrevem infecção por fungos do gênero Exophiala causando principalmente nódulos cutâneos localizados. No paciente relatado, embora as lesões fossem localizadas na face, não havia presença de lesões nodulares e a infecção se manifestou na forma de alopecia, eritema, descamação e crostas, características clínicas que são descritas com menor freqüência. No entanto, essas lesões estavam associadas com despigmentação e ulceração nasal, sinais descritos por SCOTT et al. (1996) em doenças fúngicas subcutâneas e sistêmicas como feoifomicose, blastomicose, aspergilose, prototecose, entre outras. Além disso, tais lesões não eram pruriginosas nem mesmo dolorosas, fato também discorrido por HERRÁEZ et al. (2001).

No caso aqui descrito, a ceratite concomitante às lesões dermatológicas ocorreu em ambos os olhos e de forma simétrica, o que tornava bastante improvável a origem traumática, que é citada por GELATT (2003). A utilização de terapia tópica crônica com colírio antibiótico e corticosteróide, sem melhora clínica, distanciou a possibilidade de ceratite bacteriana e alérgica, fato mencionado pelo autor supracitado, ao passo que a regressão dos sinais oftálmicos com a terapia sistêmica antifúngica, fortaleceu o diagnóstico de ceratite micótica, ainda que não tenha sido realizada cultura micológica de swab corneano.

A presença de despigmentação nasal e ulceração mucocutânea exigiram a diferenciação de 
doenças auto-imunes e neoplásicas, como o linfoma cutâneo, conforme citam SCOTT et al. (1996). Embora essas enfermidades possam cursar com alterações dermatológicas e oculares concomitantes, suas manifestações oftálmicas são, na maioria das vezes, na forma de uveíte e glaucoma, respectivamente (SCOTT et al., 1996), e não como a ceratite acima relatada. Essas doenças foram descartadas nesse paciente por meio da análise histopatológica do tecido obtido por biópsia. Além disso, SCOTT et al. (1996) afirmam que lesões localizadas na região facial de um cão jovem exigem investigação de demodicose, ratificando aqui a importância do exame parasitológico de pele, que se mostrou negativo para ácaros cutâneos.

As dermatites nodulares granulomatosas, como a identificada no exame histopatológico da biópsia cutânea desse cão, podem ter etiologia infecciosa ou não-infecciosa. As causas não-infecciosas são comumente vistas na foliculite e na furunculose ou então em casos de reação a corpo estranho (CONCEIÇÃO et al., 2004). Nesse paciente não foi identificado, ao exame clínico, marcador de infecção bacteriana como pústulas e colaretes epidérmicos, nem mesmo a presença de corpo estranho, no entanto, as lesões encontradas no exame histopatológico justificam-se pelo crescimento de Exophiala sp na cultura fúngica, haja vista que a dermatomicose, a actinomicose, a feoifomicose, a blastomicose e a nocardiose são vistas como causas infecciosas dessas lesões histopatológicas (CONCEIÇÃO et al., 2004).

Não foi observado ao exame histopatológico a presença de hifas fúngicas possivelmente porque o tratamento com cetoconazol realizado anterior à biópsia cutânea tenha surtido efeito. Além disso, os fungos dematiáceos são pigmentados por melanina e a quantidade de melanina produzida depende da disponibilidade de nutrientes, idade e viabilidade do organismo. Sendo assim, com a morte do organismo esse pode não aparecer pigmentado na coloração de hematoxilina e eosina, exigindo-se então as colorações especiais (HERRÁEZ et al., 2001).

A cultura fúngica foi indispensável no caso em questão, pois possibilitou a identificação do agente e a definição da terapia a ser empregada. Exophiala sp já foi isolado de algumas micoses cutâneas em gatos, porém os relatos em caninos são escassos (SCOTT et al., 1996), apresentando-se aqui um caso incomum dessa entidade. Além do mais, o isolamento de Alternaria sp posterior ao primeiro tratamento pode ser atribuído à característica oportunista desse microorganismo, haja vista que ele compõe parte da microbiota fúngica normal (MARIN, 2006) e esse último poderia estar contribuindo para a resistência ao primeiro tratamento.
O manejo das infecções micóticas pode ser dificultado pelo fato de que fungos são organismos eucarióticos e fármacos que são tóxicos às células fúngicas, são também freqüentemente tóxicos às células eucarióticas do hospedeiro (PUKAY \& DION, 1984). O cetoconazol é descrito apresentando maiores efeitos tóxicos que o itraconazol (MEDLEAU et al., 1995), fato também observado no paciente deste relato. Entre os efeitos colaterais desses fármacos, MEDLEAU et al. (1995) destacam a anorexia, o vômito, como foi observado no cão ora relatado, a diarréia e a icterícia, em virtude da alta hepatotoxicidade.

Conclui-se que as lesões dermatológicas causados por Exophiala sp são inespecíficas e a realização de cultura fúngica acompanhada por biópsia de pele permite o diagnóstico de dermatomicose e ceratite fúngica. Além disso, o emprego terapêutico de itraconazol sistêmico pode ser efetivo na cura de dermatite e ceratite micótica por Exophiala sp no cão.

\section{FONTES DE AQUISIÇÃO}

${ }^{a}$ Cimed Indústria de Medicamentos Ltda. São Paulo/SP.

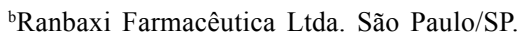

\section{REFERÊNCIAS}

BERNAYS, M.E.; PEIFFER, Jr.R.L. Ocular infections with dematiaceous fungi in two cats and a dog. Journal of American Veterinary Medical Association, v.213, n.4, p.507-509, 1998.

BONIFAZ, A. Treating chromoblastomycosis with systemic antifungals. Expert Opin Pharmacother, v.5, n.2, p.247$254,2004$.

BOULJIHAD, M. et al. Pyogranulomatous meningoencephalitis associated with dematiaceous fungal (Cladophialophora bantiana) infection in a domestic cat. Journal of Veterinary Diagnostic Investigation, v.14, n.1, p.70-72, 2002.

CASTRO, L.G.M. et al. Células fúngicas permanecem viáveis por até doze dias em lesões de cromomicose tratadas pela criocirurgia com nitrogênio líquido. Anais Brasileiros de Dermatologia, v.78, n.3, p.1-7, 2003.

CONCEIÇÃO, L.G. et al. Biópsia e histopatologia da pele: um valioso recurso diagnóstico na dermatologia - revisão -parte 2. Clínica Veterinária, v.9, n.52, p.28-40, 2004.

CORRADO, M.L. et al. Susceptibility of dermatiaceous fungi to amphotericin $\mathrm{B}$, miconazole, ketoconazole, flucytosine and rifampin alone and in combination. Sabouraudia, v.20, n.2, p.109-113, 1982.

FERREIRA, L.M. et al. Caso para diagnóstico. Anais Brasileiro de Dermatologia, v.81, n.3, p.1-5, 2006.

GARCIA-MARTOS, P. et al. Human infections by black yeasts of genus Exophiala. Revista Iberoamericana de Micología, v.19, n.2, p.72-79, 2002.

Ciência Rural, v.38, n.7, out, 2008. 
GELATT, K.N. Doenças e cirurgia da córnea e esclera do cão. In: Manual de oftalmologia veterinária. Barueri: Manole, 2003. p.125-164.

HERRÁEZ, P. et al. Invasive phaeohyphomycosis caused by Curvularia species in a dog. Veterinary Pathology, v.38, n.4, p.456-459, 2001.

JAND, S.K.; GUPTA, M.P. Dermatomycosis in dogs. Mycoses, v.32, n.2, p.104-105, 1989.

KANO R. et al. First isolation of Exophiala dermatitidis from a dog: identification by molecular analysis. Veterinary Microbiology, v.76, n.2, p.201-205, 2000.

KETTLEWELL, P. et al. Phaeohyphomycosis caused by Exophiala spinifera in two cats. Journal of Medical and Veterinary Mycology, v.27, n.4, p.257-264, 1989.

MARIN, M.I. et al. Cutaneous alternariosis and its diagnosis in an inmunocompromised patient. Anales de Medicina interna, v.23, n.1, p.26-27, 2006.
MEDLEAU, L. et al. Itraconazole for the treatment of cryptococcosis in cats. Journal of Veterinary Internal Medicine, v.9, n.1, p.39-42, 1995

NEGRONI, R. et al. Posaconazole treatment of refractory eumycetoma and chromoblastomycosis. Revista do Instituto de Medicina Tropical de São Paulo, v.47, n.6, p.1-17, 2005. PUKAY, B.P.; DION, W.M. Feline phaeohyphomycosis: treatment with ketaconazole and 5-fluorocytosine. Canadian Veterinary Journal, v.25, n.3, p.130-134, 1984.

ROCHETTE, F. et al. Antifungal agents of use in animal health - practical applications. Journal of the Veterinary Pharmacology Therapy, v.26, n.1, p.31-53, 2003.

SCOTT, D.W. et al. Doenças fúngicas da pele. In: Dermatologia de pequenos animais. Rio de Janeiro: Interlivros, 1996. p.301-359.

SILVA, M.R.R. et al. Subcutaneous phaeohyphomycosis by Exophiala jeanselmei in a cardiac transplant recipient. Revista do Instituto de Medicina Tropical de São Paulo, v.47, n.1, p. $1-5,2005$.

SUH, M.K. Phaeohyphomycosis in Korea. Japanese Journal of Medical Mycology Tokyo, v.46, p.67-70, 2005. 